\title{
Less invasive ventilation in extremely low birth weight infants from 1997 to 2011: survey versus evidence
}

\author{
Roland Gerull ${ }^{1}$ - Helen Manser ${ }^{1} \cdot$ Helmut Küster $^{3} \cdot$ Tina Arenz $^{2}$ • \\ Stephan Arenz ${ }^{1} \cdot$ Mathias Nelle $^{1}$
}

Received: 22 December 2014 /Revised: 6 March 2015 / Accepted: 9 March 2015 / Published online: 1 April 2015

(C) Springer-Verlag Berlin Heidelberg 2015

\begin{abstract}
Evidence for target values of arterial oxygen saturation $\left(\mathrm{SaO}_{2}\right), \mathrm{CO}_{2}$, and $\mathrm{pH}$ has changed substantially over the last 20 years. A representative survey concerning treatment strategies in extremely low-birth-weight infants (ELBW) was sent to all German neonatal intensive care units (NICUs) treating ELBW infants in 1997. A follow-up survey was conducted in 2011 and sent to all NICUs in Germany, Austria, and Switzerland. During the observation period, NICUs targeting $\mathrm{SaO}_{2}$ of 80,85 , and $90 \%$ have increased, while units aiming for 94 and $96 \%$ decreased (all $p<0.001$ ). Similarly, NICUs aiming for $\mathrm{pH} 7.25$ or lower increased, while 7.35 or higher decreased (both $p<0.001$ ). Furthermore, more units targeted a $\mathrm{CO}_{2}$ of $50 \mathrm{mmHg}(7.3 \mathrm{kPa})$ or higher $(p<0.001)$, while fewer targeted 40 or $35 \mathrm{mmHg}$ $(p<0.001)$. Non-invasive ventilation (NIV) was used in $80.2 \%$ of NICUs in 2011. The most frequently used ventilation modes were synchronized intermittent mandatory ventilation (SIMV) $(67.5 \%)$ and intermittent positive pressure ventilation (IPPV) (59.7\%) in 1997 and SIMV (77.2 \%) and synchronized intermittent positive pressure ventilation (SIPPV) (26.8\%) in 2011. NICUs reporting frequent or always use of IPPV decreased to
\end{abstract}

Electronic supplementary material The online version of this article (doi:10.1007/s00431-015-2519-3) contains supplementary material, which is available to authorized users.

\section{Roland Gerull}

roland.gerull@insel.ch

Helen Manser

Helen_manser@hotmail.com

Helmut Küster

Helmut.Kuester@med.uni-goettingen.de

Tina Arenz

Tina.arenz@gmx.de

Stephan Arenz

Stephan.arenz@gmx.de
$11.0 \%$ ( $p<0.001)$. SIMV (77.2 \%) and SIPPV (26.8 \%) did not change from 1997 to 2011, while high-frequency oscillation (HFO) increased from 9.1 to $19.7 \%(p=0.018)$. Differences between countries, level of care, and size of the NICU were minimal.

Conclusions: Target values for $\mathrm{SaO}_{2}$ decreased, while $\mathrm{CO}_{2}$ and $\mathrm{pH}$ increased significantly during the observation period. Current values largely reflect available evidence at time of the surveys.

\section{What is Known:}

- Evidence concerning target values of oxygen saturation, $\mathrm{CO}_{2}$, and $\mathrm{pH}$ in extremely low-birth-weight infants has grown substantially.

- It is not known to which extent this knowledge is transferred into clinical practice and if treatment strategies have changed.

\section{What is New:}

- Target values for oxygen saturation in ELBW infants decreased between 1997 and 2011 while target values for $\mathrm{CO}_{2}$ and $\mathrm{pH}$ increased.

- Similar treatment strategies existed in different countries, hospitals of different size, or university versus nonuniversity hospitals in 2011.

Mathias Nelle

mathias.nelle@insel.ch

1 Division of Neonatology, University Children's Hospital Inselspital Bern, 3010 Bern, Switzerland

2 Department of Pediatrics, University Children's Hospital Inselspital Bern, 3010 Bern, Switzerland

Division of Neonatology, University Children's Hospital Göttingen, Robert-Koch-Straße 40, 37099 Göttingen, Germany 
Keywords Preterm - ELBW · Survey · Oxygen saturation · $\mathrm{CO}_{2} \cdot \mathrm{pH} \cdot$ Ventilation

$\begin{array}{ll}\text { Abbreviations } \\ \text { BIPAP } & \text { Biphasic positive airway pressure ventilation } \\ \mathrm{BPD} & \text { Bronchopulmonary dysplasia } \\ \mathrm{ELBW} & \text { Extremely low birth weight, less than } 1000 \mathrm{~g} \\ \mathrm{FiO}_{2} & \text { Fraction of inspired oxygen } \\ \mathrm{GA} & \text { Gestational age } \\ \mathrm{GNPI} & \text { Gesellschaft für Neonatologie und pädiatrische } \\ & \text { Intensivmedizin, Society of Neonatology and } \\ & \text { Pediatric Intensive Care } \\ \mathrm{IVH} & \text { Intraventricular hemorrhage } \\ \mathrm{IMV} & \text { Intermittent mandatory ventilation } \\ \mathrm{IPPV} & \text { Intermittent positive pressure ventilation } \\ \mathrm{NICU} & \text { Neonatal intensive care unit } \\ \mathrm{NIV} & \text { Non invasive ventilation } \\ \text { pCO } & \text { Partial pressure of carbon dioxide } \\ \mathrm{PEEP} & \text { Positive end expiratory pressure } \\ \mathrm{PiP} & \text { Peak inspiratory pressure } \\ \mathrm{RDS} & \text { Respiratory distress syndrome } \\ \mathrm{SaO} & \text { Arterial oxygen saturation } \\ \mathrm{SIMV} & \text { Synchronized intermittent mandatory ventilation } \\ \mathrm{SIPPV} & \text { Synchronized Intermittent positive pressure } \\ & \text { ventilation } \\ \mathrm{VG} & \text { Volume guarantee ventilation } \\ \mathrm{VLBW} & \text { Very low birth weight, less than } 1500 \mathrm{~g} \\ & \end{array}$

\section{Introduction}

In Western Europe, 5-10 \% of newborn infants are born prematurely defined as birth at a gestational age of less than 37 completed weeks. The majority of preterm infants are born between 34 and 37 weeks, and of these, around $5 \%$ is born before 28 weeks [3]. The smallest preterm infants with a birth weight of less than $1000 \mathrm{~g}$ (extremely low-birth-weight (ELBW) infants) have the highest risk for long-term morbidity and mortality. One of the major long-term morbidities is the development of bronchopulmonary dysplasia (BPD) which is associated with prolonged hospitalization, increased use of medications, more frequent re-hospitalizations, and impaired neurodevelopmental outcome $[8,32,24]$. Since the development of BPD is increased with prolonged ventilation [13], changes of target values for oxygen saturation, $\mathrm{pCO}_{2}$, and $\mathrm{pH}$ might have an impact on the duration of mechanical ventilation and thereby on the development of BPD.

Furthermore, increased oxygen saturation is associated with the development of retinopathy of prematurity [2]. Several publications have described this correlation and tried to establish optimal ranges for oxygen saturation.
During the last 15 years, guidelines and recommendations for neonatal care have changed substantially to account for results of many prospective trials published during this period $[5,25,21]$. However, it remains largely unknown if guidelines and recommendations have been implemented into local treatment algorithms. Therefore, we performed a representative, standardized survey in Germany in 1997 and a follow-up survey in all German-speaking countries (Germany, Austria, and Switzerland) in 2011 assessing changes in care of ELBW infants. This paper summarizes results on mechanical ventilation and target values for oxygen saturation, $\mathrm{pCO}_{2}$, and $\mathrm{pH}$.

\section{Methods}

Detailed description of methods has been published previously [9]. In brief, two surveys concerning routine management of preterm infants with a birth weight between 750 and $1000 \mathrm{~g}$ were performed in 1997 in Germany and in 2011 in all neonatal intensive care units (NICUs) in Germany, Austria, and Switzerland, including all Swiss centers with other languages. The questionnaire contained approximately 100 detailed questions about treatment of ELBW infants as well as questions characterizing the department approached. Both questionnaires were sent to the head of the individual NICUs, and it was expected to be answered by the head or a leading representative. The second questionnaire was a shortened version of the first questionnaire with identical wording of remaining questions. It was transferred to the online survey software Unipark (Globalpark AG, Cologne, Germany). It was sent via email to all German $(n=171)$, Austrian $(n=15)$, and Swiss $(n=9)$ hospitals treating very-low-birth-weight (VLBW, birth weight less than $1500 \mathrm{~g}$ ) infants. Non-responding institutions were reminded twice by mail and then once by telephone.

Answers from the first survey were transferred to and analyzed with Microsoft Excel (2007) and SPSS 19.0 (SPSS Inc., Chicago, USA). Unconditional confidence interval on difference of proportions [1] was used to compare results of the two surveys. To compare categorical subgroups of the 2011 survey, Fisher's exact test was used for comparison of two subgroups and Freeman-Halton test was applied to compare three subgroups. Missing values were excluded from analysis. Results with an alpha error of $p<0.05$ were considered significant.

Frequencies of therapy were categorized as "never," "rare, " "frequent," or "always." Unless otherwise specified, the combined responses of never and rare were compared to the combined frequencies of frequent and always. For comparison, intensive care units were categorized into university and non-university hospitals. Small, medium, and large NICUs were arbitrarily defined as units with annual admissions of $\leq 12,13-30$, and $>30$ ELBW infants, respectively. 
To improve response rates, a financial incentive was paid by hospital funds (Ludwig-Maximilians-University Munich, Germany, in 2007 and Inselspital Berne, Switzerland, in 2011).

\section{Results}

Response rate In 1997, 332 hospitals were approached and $211(63.6 \%)$ responded. Of these, 46 did not treat ELBW infants, 36 were excluded because they treated less than ten VLBW per year, and three responded but declined participation. This resulted in 126 units in the first survey of whom a complete questionnaire was available for analysis.

In 2011, 195 neonatal departments were approached and 129 answered (66.2 \%). Response rates for Germany, Switzerland, and Austria were 110/171 (64.3\%), 9/9 (100\%), and $10 / 15(66.7 \%)$, respectively. The response rate was higher in Switzerland than in Germany $(p=0.029)$, whereas no significant difference existed between Germany versus Austria ( $p=$ $1.000)$ and Austria versus Switzerland $(p=0.118)$.

Changes over time Target values for $\mathrm{SaO}_{2}, \mathrm{pCO}_{2}$, and $\mathrm{pH}$ changed significantly during the observation period as shown in Figs. 1, 2, and 3. In 2011, target values for $\mathrm{CO}_{2}$ of 50 $80 \mathrm{mmHg}(6.7-10.7 \mathrm{kPa})$ (all $p<0.001)$ were more frequently in the target range of the responding NICUs compared to 1997. In contrast, $35 \mathrm{mmHg}(4.7 \mathrm{kPa})$ and $40 \mathrm{mmHg}(5.3$ $\mathrm{kPa}$ ) were less frequently within the target range (both $p<0.001$ ), showing a general trend to higher $\mathrm{CO}_{2}$. In line with these results is a lower $\mathrm{pH}$ target: a $\mathrm{pH}$ of 7.35, 7.40, and 7.45 was less frequently in the target range (both $p=0.003, p=$ 0.003 , and $p<0.001$, respectively), while more NICUs aimed for 7.20 and 7.25 (both $p<0.001$ ) in 2011. Target values for $\mathrm{SaO}_{2}$ also changed significantly from 1997 to 2011 with more units targeting 80, 85, and $90 \%(p<0.001, p<0.001$, and $p=$ 0.001 , respectively) and fewer units aiming for 94 and $96 \%$ (both $p<0.001$ ) in 2011.

Changes of invasive and non-invasive ventilation between 1997 and 2011 are shown in Table 1. Of the invasive modes of ventilatory support, synchronized intermittent mandatory ventilation (SIMV), intermittent positive pressure ventilation (IPPV), and synchronized intermittent positive pressure ventilation (SIPPV) were the most frequently used ventilation modes in 1997 with 67.5, 59.7, and $33.3 \%$, of the NICUs applying these modes always or frequently. In 2011, units reporting frequent or always use of IPPV decreased to $11.0 \%(p<0.001)$, while SIMV $(77.2 \%)$ and SIPPV (26.8 \%) did not change significantly in comparison to 1997 . NICUs reporting frequent or always application of non-synchronized ventilation and high-frequency oscillation (HFO) changed significantly between 1997 and 2011: IPPV declined from 59.7 to
$11.0 \%(p<0.001)$ whereas HFO increased from 9.1 to $19.7 \%(p=0.018)$. More advanced modes like volume guarantee, proportional assist ventilation, and biphasic positive airway pressure (BIPAP) were not assessed in 1997. In 2011, these techniques were applied frequently or always in $20.9,7.9$ and $4.7 \%$ of the units, respectively.

In 2011, non-invasive ventilatory (NIV) support was used in $80.2 \%$ of NICUs. Pharyngeal tube, mask, and prongs were used for NIV in 50.4, 76.8, and 97.6\%, respectively. Comparing the combined rare, frequent, and always application of NIV modes shows that noninvasive IPPV (NIPPV) $(37.6 \%)$ and noninvasive SIMV (NSIMV) (26.3\%) were the most frequently used ventilatory modes in 1997. In 2011, these were noninvasive BIPAP (NBIPAP) (34.9\%), NSIMV (34.9\%), and NIPPV (27.0\%).

Size of the unit Analyses revealed only two differences between NICUs of different size: IPPV was used less frequently in small units $(p=0.005)$, and the frequency of NICUs never using prongs for non-invasive ventilation was also lower in small units $(p=0.031)$.

Level of care Differences between university hospitals and non-university hospitals were minimal: university hospitals used intermittent positive pressure ventilation (IPPV) ( $21.9 \%$ vs. $7.4 \% ; p=0.044)$ and considered an oxygen saturation of $80 \%$ in the target range more frequently than nonuniversity hospitals (29.0 vs. $11.7 \% ; p=0.044)$.

Countries In 2011, an oxygen saturation of 90 and $92 \%$ was less frequently within the target range in Switzerland, while a saturation of $96 \%$ was more frequently targeted in Austria ( $p=0.034, p=0.034$, and 0.027 , respectively). Of the invasive modes of ventilatory support, SIPPV and volume guaranty (VG) were used more often in Austria compared to Germany and Switzerland ( $p=0.005$ and $p=0.010$, respectively). NIV was used more frequently $(p=0.015)$ and was more frequently applied by pharyngeal tube $(p<0.001)$ in Germany compared to Austria and Switzerland. For NIV, NISIMV was used in more NICUs in Germany ( $p=0.035)$, while fewer units never applied NBIPAP $(p=0.023)$.

\section{Discussion}

The results of this representative survey show that modes of mechanical ventilation and target values for $\mathrm{SaO}_{2}, \mathrm{CO}_{2}$, and pH for ELBW infants changed significantly between 1997 and 2011.

The response rate of $63.6 \%$ for all centers treating ELBW in 1997 in Germany and a combined response rate of $66.2 \%$ in Germany, Austria, and Switzerland in 2011 make this survey representative for German-speaking countries. The response 
Fig. 1 Target values for $\mathrm{SaO}_{2}$ during the observation period (1997-2011)

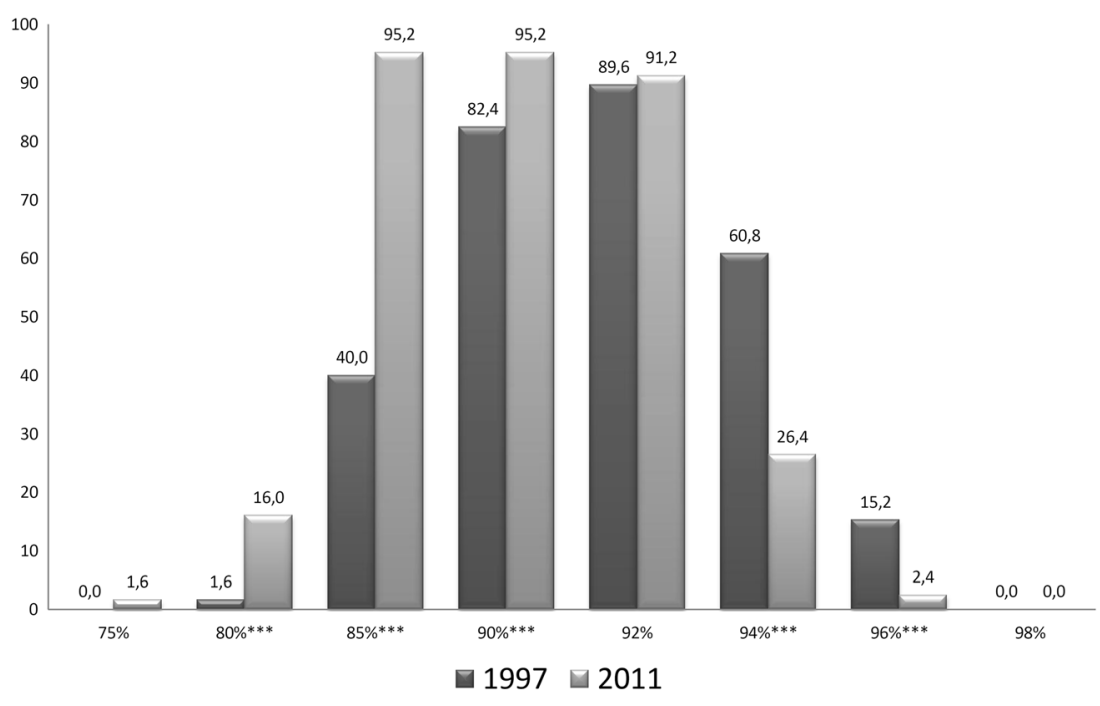

rate is comparable with other surveys in critical care medicine [7]. Differences between university and non-university hospitals and differences between countries were minimal. Therefore, the higher response rates of university hospitals and Switzerland are unlikely to lead to a relevant bias.

Results of this survey show that target values for $\mathrm{SaO}_{2}$ decreased significantly between 1997 and 2011 for ELBW infants. During the observation period, several studies showed the association between higher $\mathrm{SaO}_{2}$ and the development of retinopathy of prematurity (ROP). Furthermore, a lower $\mathrm{SaO}_{2}$ might seem more physiological for ELBW infants because intrauterine oxygenation has been shown to be much lower with preductal $\mathrm{SaO}_{2}$ and postductal $\mathrm{SaO}_{2}$ around 70 and $65 \%$, respectively. Therefore, it seemed reasonable to tolerate lower $\mathrm{SaO}_{2}$ in spite of absence of guidelines that recommend precise target values.
Large and well-designed studies have been published within the last 4 years that show that higher $\mathrm{SaO}_{2}$ leads to a higher incidence of ROP but show a higher mortality in patients with a lower $\mathrm{SaO}_{2}[26,4]$, while one other large trial did not show such results [23]. However, a recent meta-analysis confirmed that lower $\mathrm{SaO}_{2}$ is associated with higher mortality [22]. It is important to notice that our survey was performed before these trials were published, and we expect that relevant changes of target values for $\mathrm{SaO}_{2}$ occurred thereafter. Thus, target values assessed by our survey might already be outdated and have been replaced by higher values.

Hypercapnia leads to cerebral vasodilatation and increased cerebral blood flow and might cause intraventricular hemorrhage (IVH) by rupture of germinal matrix vessels [16]. Over the last 35 years, hypercapnia was repeatedly reported to be associated with IVH. However, the majority of studies were
Fig. 2 Target values for $\mathrm{pCO}_{2}$ during the observation period (1997-2011)

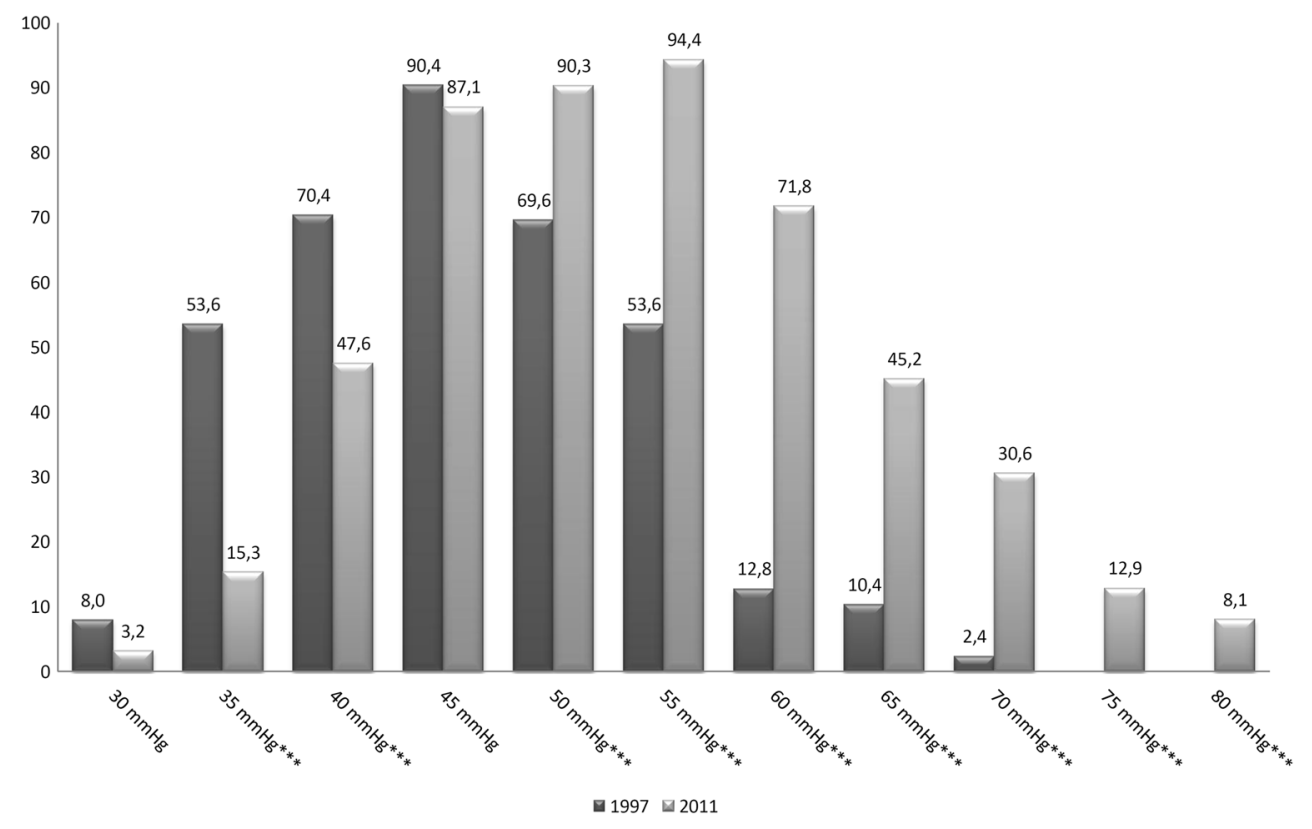


Fig. 3 Target values for $\mathrm{pH}$ during the observation period (1997-2011)

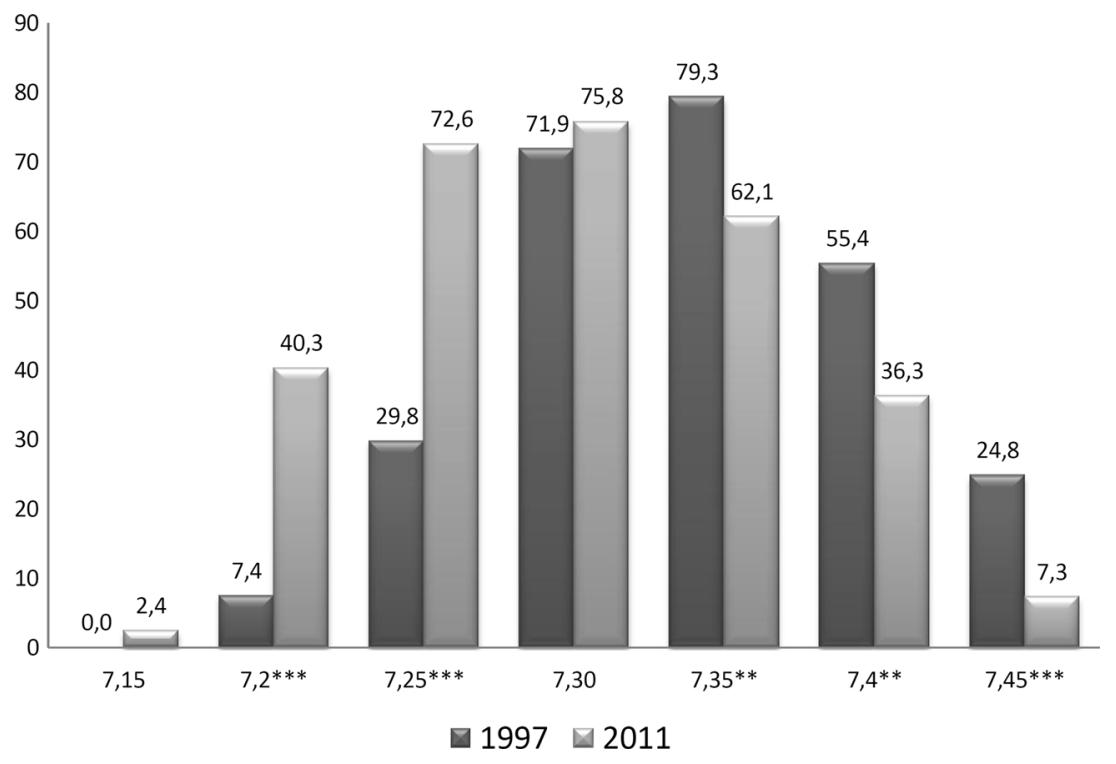

performed retrospectively and prospective randomized trials are lacking. Furthermore, the association was mostly described in univariate analyses [6, 27], while it disappeared in multivariate analyses $[33,15]$. One larger and more recently published trial found that $\mathrm{pCO}_{2}$ is a dose-dependent predictor of severe IVH, but the authors concluded that they could not determine causality and that "perhaps, hypercapnia during the surfactant and permissive hypercapnia eras still characterizes infants with the most severe acute lung disease" [11]. Therefore, while a trend to permissive hypercapnia can clearly be seen in our data, its safety concerning IVH needs to be proven.

Over the last years, a concept of "gentle ventilation" has increasingly been studied. This concept includes administration of limited plateau pressures, low tidal volumes, and permissive hypercapnia as well as tolerating a lower $\mathrm{pH}$. It has been shown that mechanical ventilation with lower tidal

Table 1 Changes of ventilation strategies in extremely low-birth-weight infants between 1997 and 2011

\begin{tabular}{|c|c|c|c|c|c|c|c|}
\hline & 1997 & & 2011 & & Estimated difference (\%) & $95 \% \mathrm{CI}$ & $p$ value \\
\hline \multicolumn{8}{|c|}{ Non-invasive ventilation (NIV) } \\
\hline Use NIV & & & $101 / 126$ & $80.2 \%$ & & & \\
\hline CPAP & $123 / 127$ & $96.7 \%$ & $123 / 126$ & $97.6 \%$ & +0.9 & $-4.3 \% ; 6.0 \%$ & 0.793 \\
\hline IPPV & $8 / 117$ & $6.8 \%$ & $11 / 126$ & $8.7 \%$ & +1.9 & $-5.3 \% ; 9.2 \%$ & 0.601 \\
\hline $\mathrm{HFO}$ & $0 / 111$ & $0.0 \%$ & $2 / 126$ & $1.6 \%$ & +1.6 & $-2.1 \% ; 6.0 \%$ & 0.224 \\
\hline SIPPV & $4 / 110$ & $3.6 \%$ & $4 / 126$ & $3.2 \%$ & -0.4 & $-6.3 \% ; 4.9 \%$ & 0.884 \\
\hline SIMV & $5 / 114$ & $4.4 \%$ & $12 / 126$ & $9.5 \%$ & +5.1 & $-1.6 \% ; 12.4 \%$ & 0.125 \\
\hline BIPAP & & & $20 / 126$ & $15.9 \%$ & & & \\
\hline \multicolumn{8}{|c|}{ Device for CPAP/non-invasive ventilation } \\
\hline Pharyngeal tube & & & $63 / 125$ & $50.4 \%$ & & & \\
\hline Mask & & & $96 / 125$ & $76.8 \%$ & & & \\
\hline Prongs & & & $122 / 125$ & $97.6 \%$ & & & \\
\hline \multicolumn{8}{|c|}{ Mechanical ventilation } \\
\hline IPPV & $72 / 119$ & $59.7 \%$ & $14 / 127$ & $11.0 \%$ & -48.7 & $-59.2 \% ;-38.6 \%$ & $<0.001$ \\
\hline HFO & $11 / 121$ & $9.1 \%$ & $25 / 127$ & $19.7 \%$ & +10.6 & $1.9 \% ; 19.6 \%$ & 0.018 \\
\hline SIPPV & $40 / 120$ & $33.3 \%$ & $34 / 127$ & $26.8 \%$ & -6.5 & $-18.1 \% ; 5.0 \%$ & 0.274 \\
\hline SIMV & $83 / 123$ & $67.5 \%$ & $98 / 127$ & $77.2 \%$ & +9.7 & $-1.5 \% ; 20.8 \%$ & 0.089 \\
\hline BIPAP & & & $6 / 127$ & $4.7 \%$ & & & \\
\hline VG & & & $26 / 127$ & $20.5 \%$ & & & \\
\hline Prop assist & & & $10 / 127$ & $7.9 \%$ & & & \\
\hline
\end{tabular}

Bold entries highlight significant results $(\mathrm{p}<0.05)$ 
volumes leads to decreased inflammation and cytokine expression [19] and to decreased mortality in adults [30, 31]. While well-designed randomized trials in preterm infants are scarce [17], there is a large body of evidence from animal research, biochemical concepts, and trials in human adults indicating that this concept is safe and beneficial for preterm infants. A meta-analysis comparing volume-targeted ventilation to pressure-limited ventilation in preterm infants showed several advantages of volume-targeted ventilation, including reduced risks for death or BPD, pneumothorax, and intracranial hemorrhage [34]. These results suggest that gentle ventilation with limited tidal volumes is beneficial. Furthermore, recommendations for newborn infants with lung hypoplasia in form of congenital diaphragmatic hernia, who also have very fragile lungs, include these considerations and also seem to be associated with lower morbidity and mortality [20]. Several studies show an association between mechanical ventilation and the development of BPD in preterm infants. Therefore, reduced time of, or even avoidance of, mechanical ventilation is aimed for, which implies permissive hypercapnia and lower $\mathrm{pH}$. Results of this survey mirror the given evidence showing significant changes of local treatment algorithms to target values of higher $\mathrm{CO}_{2}$ and lower $\mathrm{pH}$.

A different concept in avoidance of mechanical ventilation is the application of mechanical ventilation via pharyngeal tube, mask, or prongs without tracheal intubation (NIV). Several studies evaluated NIV concerning successful extubation and time on mechanical ventilation. Results showed a reduced risk for extubation failure and reintubation [14]. Fewer intubations in the delivery room have been reported [18]. A recent large study showing that NIV is not associated with decreased risk of BPD [12] was not yet published when the survey was performed. The survey did not assess the number of NICUs using NIV in 1997. However, $80.2 \%$ of units stated that they were using NIV in 2011, showing that this concept is implemented in local treatment algorithms to a large extent.

Surveys on patient management are frequently performed in medicine. A crucial question is if they reflect what is actually done at the bedside. A survey such as ours cannot assess to what extent responses reflect actual practice, in contrast to general knowledge of the responding individual. This can probably be considered to be the most relevant weakness of our study. However, a recent European cross-sectional study showed that hypocapnia is a relatively uncommon finding in preterm infants whereas hypercapnia occurs comparably frequently [28]. Furthermore, a different study which was performed at the time of our survey showed that newer ventilation modes are used infrequently [29]. Results of these publications are in line with the results of our survey making it more likely that our survey reflects actual practice. On the other hand, significant differences between knowledge about preterm care and its application in practice have been described [10].
In summary, this survey provides valuable information about changes of respiratory target values between 1997 and 2011. Furthermore, it describes changes of used modes of mechanical ventilation and shows that current knowledge and concepts have been implemented into local treatment strategies.

\section{Conclusion}

The presented results of our surveys show that target values of $\mathrm{SaO}_{2}, \mathrm{CO}_{2}$, and $\mathrm{pH}$ for ELBW infants changed significantly between 1997 and 2011, aiming for lower $\mathrm{SaO}_{2}$, higher $\mathrm{CO}_{2}$, and lower $\mathrm{pH}$. Furthermore, NIV is used in the majority of NICUs, showing that concepts of lung protective ventilation have been implemented into local treatment strategies. Treatment strategies are similar between German-speaking countries, NICUs of different size, and different level of care in 2011.

Conflict of interest The authors have no conflicts of interest relevant to this article to disclose.

Funding No sources of external funding

Authors' contributions The authors contributed to the manuscript in the following way: Roland Gerull was involved in the design of the second questionnaire, center recruitment, and data analysis and wrote the manuscript. Helen Manser was responsible for the second questionnaire in terms of design, development of the database, and data management and center recruitment. Tina Arenz was responsible for development and realization of the first survey. Helmut Küster supervised the development and contributed to the realization of the first survey. Stephan Arenz was responsible for center recruitment, development of the database of the second questionnaire, and data analysis and wrote parts of the manuscript. Mathias Nelle supervised the development and realization of the second survey, acquired hospital funds for the incentive, and was involved in writing the manuscript. All authors have participated in the concept and design, analysis and interpretation of data, and drafting or revising of the manuscript and contributed in discussions, reviews, and corrections of the submitted manuscript. All listed authors on the manuscript have seen and approved the submitted version of the manuscript and take full responsibility for the manuscript.

\section{References}

1. Agresti A, Min Y (2001) On small-sample confidence intervals for parameters in discrete distributions. Biometrics 57(3):963-971

2. Askie LM, Henderson-Smart DJ, Ko H (2009) Restricted versus liberal oxygen exposure for preventing morbidity and mortality in preterm or low birth weight infants. Cochrane Database Syst Rev 1, CD001077. doi:10.1002/14651858.CD001077.pub2

3. Blencowe H, Cousens S, Oestergaard MZ, Chou D, Moller AB, Narwal R, Adler A, Vera Garcia C, Rohde S, Say L, Lawn JE (2012) National, regional, and worldwide estimates of preterm birth rates in the year 2010 with time trends since 1990 for selected 
countries: a systematic analysis and implications. Lancet 379(9832):2162-2172. doi:10.1016/S0140-6736(12)60820-4

4. Carlo WA, Finer NN, Walsh MC, Rich W, Gantz MG, Laptook AR, Yoder BA, Faix RG, Das A, Poole WK, Schibler K, Newman NS, Ambalavanan N, Frantz ID 3rd, Piazza AJ, Sanchez PJ, Morris BH, Laroia N, Phelps DL, Poindexter BB, Cotten CM, Van Meurs KP, Duara S, Narendran V, Sood BG, O'Shea TM, Bell EF, Ehrenkranz RA, Watterberg KL, Higgins RD (2010) Target ranges of oxygen saturation in extremely preterm infants. N Engl J Med 362(21): 1959-1969. doi:10.1056/NEJMoa0911781

5. Cheong JL, Anderson P, Roberts G, Duff J, Doyle LW (2013) Postnatal corticosteroids and neurodevelopmental outcomes in extremely low birthweight or extremely preterm infants: 15-year experience in Victoria, Australia. Arch Dis Child Fetal Neonatal Ed 98(1):F32-F36. doi:10.1136/fetalneonatal-2011-301355

6. Cooke RW (1981) Factors associated with periventricular haemorrhage in very low birthweight infants. Arch Dis Child 56(6):425431

7. Duffett M, Burns KE, Adhikari NK, Arnold DM, Lauzier F, Kho ME, Meade MO, Hayani O, Koo K, Choong K, Lamontagne F, Zhou Q, Cook DJ (2012) Quality of reporting of surveys in critical care journals: a methodologic review. Crit Care Med 40(2):441449. doi:10.1097/CCM.0b013e318232d6c6

8. Ehrenkranz RA, Walsh MC, Vohr BR, Jobe AH, Wright LL, Fanaroff AA, Wrage LA, Poole K (2005) Validation of the National Institutes of Health consensus definition of bronchopulmonary dysplasia. Pediatrics 116(6):1353-1360. doi: 10.1542/peds. 2005-0249

9. Gerull R, Manser H, Kuster H, Arenz T, Nelle M, Arenz S (2013) Increase of caffeine and decrease of corticosteroids for extremely low birthweight infants with respiratory failure from 1997 to 2011 . Acta Paediatr. doi:10.1111/apa.12419

10. Iriondo M, Thio M, Buron E, Salguero E, Aguayo J, Vento M (2009) A survey of neonatal resuscitation in Spain: gaps between guidelines and practice. Acta Paediatr 98(5):786-791. doi:10.1111/ j.1651-2227.2009.01233.x

11. Kaiser JR, Gauss CH, Pont MM, Williams DK (2006) Hypercapnia during the first 3 days of life is associated with severe intraventricular hemorrhage in very low birth weight infants. J Perinatol 26(5): 279-285. doi:10.1038/sj.jp.7211492

12. Kirpalani H, Millar D, Lemyre B, Yoder BA, Chiu A, Roberts RS (2013) A trial comparing noninvasive ventilation strategies in preterm infants. N Engl J Med 369(7):611-620. doi:10.1056/ NEJMoa1214533

13. Laughon MM, Smith PB, Bose C (2009) Prevention of bronchopulmonary dysplasia. Semin Fetal Neonatal Med 14(6): 374-382. doi:10.1016/j.siny.2009.08.002

14. Lemyre B, Davis PG, De Paoli AG, Kirpalani H (2014) Nasal intermittent positive pressure ventilation (NIPPV) versus nasal continuous positive airway pressure (NCPAP) for preterm neonates after extubation. Cochrane Database Syst Rev 9, CD003212. doi: 10.1002/14651858.CD003212.pub2

15. Levene MI, Fawer CL, Lamont RF (1982) Risk factors in the development of intraventricular haemorrhage in the preterm neonate. Arch Dis Child 57(6):410-417

16. Levene MI, Shortland D, Gibson N, Evans DH (1988) Carbon dioxide reactivity of the cerebral circulation in extremely premature infants: effects of postnatal age and indomethacin. Pediatr Res 24(2):175-179. doi:10.1203/00006450-198808000-00007

17. Mariani G, Cifuentes J, Carlo WA (1999) Randomized trial of permissive hypercapnia in preterm infants. Pediatrics 104(5 Pt 1): 1082-1088

18. Meneses J, Bhandari V, Alves JG (2013) Questions concerning nasal intermittent positive-pressure ventilation vs nasal continuous positive airway pressure - reply. JAMA Pediatr 167(9):873. doi:10. 1001/jamapediatrics.2013.2212
19. Parsons PE, Eisner MD, Thompson BT, Matthay MA, Ancukiewicz M, Bernard GR, Wheeler AP (2005) Lower tidal volume ventilation and plasma cytokine markers of inflammation in patients with acute lung injury. Crit Care Med 33(1):1-6, discussion 230-232

20. Reiss I, Schaible T, van den Hout L, Capolupo I, Allegaert K, van Heijst A, Gorett Silva M, Greenough A, Tibboel D (2010) Standardized postnatal management of infants with congenital diaphragmatic hernia in Europe: the CDH EURO Consortium consensus. Neonatology 98(4):354-364. doi:10.1159/000320622

21. Ruegger C, Hegglin M, Adams M, Bucher HU (2012) Population based trends in mortality, morbidity and treatment for very pretermand very low birth weight infants over 12 years. BMC Pediatr 12: 17. doi:10.1186/1471-2431-12-17

22. Saugstad OD, Aune D (2014) Optimal oxygenation of extremely low birth weight infants: a meta-analysis and systematic review of the oxygen saturation target studies. Neonatology 105(1):55-63. doi:10.1159/000356561

23. Schmidt B, Whyte RK, Asztalos EV, Moddemann D, Poets C, Rabi Y, Solimano A, Roberts RS (2013) Effects of targeting higher vs lower arterial oxygen saturations on death or disability in extremely preterm infants: a randomized clinical trial. JAMA 309(20):21112120. doi:10.1001/jama.2013.5555

24. Short EJ, Kirchner HL, Asaad GR, Fulton SE, Lewis BA, Klein N, Eisengart S, Baley J, Kercsmar C, Min MO, Singer LT (2007) Developmental sequelae in preterm infants having a diagnosis of bronchopulmonary dysplasia: analysis using a severity-based classification system. Arch Pediatr Adolesc Med 161(11):1082-1087. doi:10.1001/archpedi.161.11.1082

25. Soll RF, Edwards EM, Badger GJ, Kenny MJ, Morrow KA, Buzas JS, Horbar JD (2013) Obstetric and neonatal care practices for infants 501 to $1500 \mathrm{~g}$ from 2000 to 2009. Pediatrics 132(2):222-228. doi:10.1542/peds. 2013-0501

26. Stenson B, Brocklehurst P, Tarnow-Mordi W (2011) Increased 36week survival with high oxygen saturation target in extremely preterm infants. N Engl J Med 364(17):1680-1682. doi:10.1056/ NEJMc1101319

27. Van de Bor M, Van Bel F, Lineman R, Ruys JH (1986) Perinatal factors and periventricular-intraventricular hemorrhage in preterm infants. Am J Dis Child 140(11):1125-1130

28. van Kaam AH, De Jaegere AP, Rimensberger PC (2013) Incidence of hypo- and hyper-capnia in a cross-sectional European cohort of ventilated newborn infants. Arch Dis Child Fetal Neonatal Ed 98(4):F323-F326. doi:10.1136/archdischild-2012-302649

29. van Kaam AH, Rimensberger PC, Borensztajn D, De Jaegere AP (2010) Ventilation practices in the neonatal intensive care unit: a cross-sectional study. J Pediatr 157(5):767-771 e761-763. doi:10. 1016/j.jpeds.2010.05.043

30. Ventilation with lower tidal volumes as compared with traditional tidal volumes for acute lung injury and the acute respiratory distress syndrome. The Acute Respiratory Distress Syndrome Network (2000). N Engl J Med 342(18):1301-1308. doi:10.1056/ NEJM200005043421801

31. Villar J, Kacmarek RM, Perez-Mendez L, Aguirre-Jaime A (2006) A high positive end-expiratory pressure, low tidal volume ventilatory strategy improves outcome in persistent acute respiratory distress syndrome: a randomized, controlled trial. Crit Care Med 34(5): 1311-1318. doi:10.1097/01.CCM.0000215598.84885.01

32. Vohr BR, Wright LL, Dusick AM, Mele L, Verter J, Steichen JJ, Simon NP, Wilson DC, Broyles S, Bauer CR, Delaney-Black V, Yolton KA, Fleisher BE, Papile LA, Kaplan MD (2000) Neurodevelopmental and functional outcomes of extremely low birth weight infants in the National Institute of Child Health and Human Development Neonatal Research Network, 1993-1994. Pediatrics 105(6):1216-1226 
33. Wallin LA, Rosenfeld CR, Laptook AR, Maravilla AM, Strand C, Campbell N, Dowling S, Lasky RE (1990) Neonatal intracranial hemorrhage: II. Risk factor analysis in an inborn population. Early Hum Dev 23(2):129-137
34. Wheeler KI, Klingenberg C, Morley CJ, Davis PG (2011) Volumetargeted versus pressure-limited ventilation for preterm infants: a systematic review and meta-analysis. Neonatology 100(3):219227. doi: $10.1159 / 000326080$ 